\title{
Actinomadura pelletieri
}

National Cancer Institute

\section{Source}

National Cancer Institute. Actinomadura pelletieri. NCI Thesaurus. Code C86106.

A species of aerobic, Gram positive bacteria assigned to the phylum Actinobacteria. This bacteria does not hydrolyze esculin, reduces nitrates, does not utilize succinate and is sensitive to lysozyme. A. pelletieri is known to cause actinomycotic mycetoma. 